\title{
Triggered Metal Ion Release and Oxidation: Ferrocene as a Mechanophore in Polymers
}

\author{
Michela Di Giannantonio, Mathieu A. Ayer, Ester Verde-Sesto, * Marco Lattuada,* \\ Christoph Weder,* and Katharina M. Fromm*
}

\begin{abstract}
The introduction of mechanophores into polymers makes it possible to transduce mechanical forces into chemical reactions that can be used to impart functions such as selfhealing, catalytic activity, and mechanochromic response. Here, an example of mechanically induced metal ion release from a polymer is reported. Ferrocene $(F c)$ was incorporated as an iron ion releasing mechanophore into poly(methyl acrylate)s (PMAs) and polyurethanes (PUs). Sonication triggered the preferential cleavage of the polymers at the $F c$ units over other bonds, as shown by a kinetic study of the molar mass distribution of the cleaved Fc-containing and Fc-free reference polymers. The released and oxidized iron ions can be detected with KSCN to generate the red-colored $\left[\mathrm{Fe}(\mathrm{SCN})_{n^{-}}\right.$ $\left.\left.\left(\mathrm{H}_{2} \mathrm{O}\right)_{6-n}\right)\right]^{(3-n)+}$ complex or reacted with $\mathrm{K}_{4}\left[\mathrm{Fe}(\mathrm{CN})_{6}\right]$ to afford Prussian blue.
\end{abstract}

$T_{\text {he development of new stimuli-responsive polymers that }}$ have the ability to change their chemical or physical properties upon application of an external stimulus such as light, ${ }^{[1]}$ temperature, ${ }^{[2]} \mathrm{pH},{ }^{[3]}$ mechanical force,${ }^{[4]}$ or redox potential is receiving considerable attention. ${ }^{[5]}$ A steadily growing number of polymeric materials have been shown to respond in a useful way to mechanical stress, allowing a wide range of chemical transformations that lead, for example, to a change in color/fluorescence ${ }^{[6]}$ the formation of proton catalysts, ${ }^{[7]}$ the generation of acids, ${ }^{[7,8]}$ and bases, ${ }^{[9]}$ and the release of small molecules. ${ }^{[10]}$ Applications of such mechanoresponsive polymeric materials include sensors, ${ }^{[11]}$ self-healing materials, ${ }^{[2]}$ drug delivery, ${ }^{[12]}$ tissue engineering, ${ }^{[13]}$ and catalysis. ${ }^{[14]}$ These polymers contain mechanophores such as spiropyran ${ }^{[6 b]}$ and azo units, ${ }^{[15]}$ as well as epoxide, ${ }^{[16]} \beta$-lactam, ${ }^{[17]}$ dioxe-

[*] M. Di Giannantonio, Prof. Dr. M. Lattuada, Prof. Dr. K. M. Fromm Department of Chemistry, University of Fribourg

Chemin du Musée 9, 1700 Fribourg (Switzerland)

E-mail:marco.lattuada@unifr.ch Katharina.fromm@unifr.ch

Dr. M. A. Ayer, Dr. E. Verde-Sesto, Prof. Dr. M. Lattuada, Prof. Dr. C. Weder

Adolphe Merkle Institute, University of Fribourg

Chemin des Verdiers 4, 1700 Fribourg (Switzerland)

E-mail: christoph.weder@unifr.ch

Dr. E. Verde-Sesto

Polymat, Joxe Mari Korta Center

University of the Basque Country UPV/EHU

Acda Tolosa 72, 20018 Donostia-San Sebastian (Spain)

E-mail: mariaester.verde@ehu.eus

(19) Supporting information and the ORCID identification number(s) for

(iD the author(s) of this article can be found under:

https://doi.org/10.1002/anie.201803524. tane,${ }^{[18]}$ and rhodamine moieties, ${ }^{[19]}$ among others. ${ }^{[20]}$ Several examples involve noncovalent (supramolecular) motifs ${ }^{[21]}$ and coordination bonds. ${ }^{[22]}$ Sijbesma and co-workers demonstrated the reversible mechanically induced dissociation of a Pd-phosphane bond embedded in a linear polymer using ultrasound. ${ }^{[23]}$ This result triggered the investigation of other mechanoresponsive polymers containing, for example, $\mathrm{Ag}^{\left[{ }^{[22]}\right.}$ and Ru-carbene complexes ${ }^{[24]}$ for catalysis. ${ }^{[10 a, 14 a, 25]}$ Further examples include metallopolymers based on telechelic cores that were end-functionalized with 2,6-bis(1'-methylbenzimidazolyl)pyridine and assembled with $\mathrm{Eu}^{3+},{ }^{[6]} \mathrm{Zn}^{2+}$, or $\mathrm{La}^{3+}$ salts. ${ }^{[27]}$

In general, the rate of chain scission upon mechanical stress exerted, for example by ultrasonication, depends on the type of mechanophore incorporated in the polymer backbone. The predetermined breaking point in a polymer can be preferentially degraded if the bond strength of the weak link is lower than that of all other bonds in the polymer chain. ${ }^{[28]}$ While there are studies on the production of Fe nanoparticles from the decomposition of ferrocene $(\mathrm{Fc})$ during sonication, surprisingly, the Fc unit has so far remained unexplored as a mechanophore in stimuli-responsive materials. ${ }^{[29]}$ The enthalpy of the heterolytic bond dissociation of this motif $\left(40 \mathrm{kcal} \mathrm{mol}^{-1}\right)^{[30]}$ is about half that of a typical covalent single bond $\left(80 \mathrm{kcal} \mathrm{mol}^{-1}\right.$ for a $\mathrm{C}-\mathrm{C}$ bond $){ }^{[31]}$ Its high susceptibility to a large number of organic reactions ${ }^{[32]}$ makes this sandwich complex useful in a wide range of applications, such as molecular sensors, ${ }^{[33]}$ in asymmetrical catalysis,${ }^{[34]}$ for electrochemical studies, ${ }^{[3]}$ and biomedical applications. ${ }^{[36]}$ Relying on previous strategies for the design of mechanically responsive polymers, we used single-electron living radical polymerizations (SET-LRP) ${ }^{[8,37]}$ to prepare poly(methyl acrylate)s having one chain-centered ferrocene motif (Fc-PMA). We further exploited a polycondensation reaction to synthesize polyurethanes ${ }^{[38]}$ with multiple, statistically distributed ferrocene moieties along the backbone (Fc-PU). ${ }^{[39]}$ The mechanoresponse of these materials was studied by monitoring the decrease of the molecular weight of these polymers, induced by ultrasonication of dilute solutions. ${ }^{[15,22,40]} \mathrm{A}$ mathematical model was used to describe the scission kinetics, while the formation of $\mathrm{Fe}^{3+}$ ions upon ultrasonication-induced release and oxidation was demonstrated by complexation with $\mathrm{KSCN}$ or $\mathrm{K}_{4}\left[\mathrm{Fe}(\mathrm{CN})_{6}\right]$ to afford the red-colored $\left[\mathrm{Fe}(\mathrm{SCN})_{n^{-}}\right.$ $\left.\left.\left(\mathrm{H}_{2} \mathrm{O}\right)_{6-n}\right)\right]^{(3-n)+}(n=1-6)$ or Prussian blue, respectively.

For a first proof of principle, a Fc-containing difunctional initiator (Scheme 1a) and, for reference purposes, the monofunctional $F c$-free initiator methyl $\alpha$-bromoisobutyrate (Scheme 1b), were used to prepare Fc-PMA and ref-PMA with number-average molecular weights $\left(M_{\mathrm{n}}\right)$ of 133 and 


$$
\text { b) }
$$

Scheme 1. Syntheses of a) the ferrocene-containing poly (methyl acrylate) (Fc-PMA) and b) the ferrocene-free poly(methyl acrylate) reference (ref-PMA). (MA = methylacrylate; $\mathrm{Me}_{6} \mathrm{TREN}=$ tris[2-(dimethylamino)ethyl]amine.)

$119 \mathrm{kDa}$, respectively, and a narrow dispersity of $Ð \approx 1.1$ (Table 1 and Figure S20). ${ }^{[8,37]}$ FTIR spectra (Figures S1 and S2) confirmed the successful preparation of all polymers (with and without ferrocene), which, together with the monomers and initiator, were also fully characterized by ${ }^{1} \mathrm{H}$ NMR and

Table 1: Description, fitting parameters, and cleavage rate constants of the sonicated ferrocene-containing and ferrocene-free polyurethanes Fc-PU and ref-PU and the ferrocene-containing and ferrocene-free poly(methyl acrylate)s Fc-PMA, ref-PMA1, and ref-PMA2.

\begin{tabular}{llllll}
\hline Polymer & $\begin{array}{c}M_{\mathrm{n}}{ }^{[\mathrm{a}]} \\
{[\mathrm{kDa}]}\end{array}$ & $\bigoplus^{[\mathrm{a}, \mathrm{b}]}$ & $\begin{array}{c}\mathrm{Fc} \\
\mathrm{no} .^{[\mathrm{c}]}\end{array}$ & \multicolumn{2}{c}{$\begin{array}{c}\text { Cleavage rate } \\
\text { constants }^{[\mathrm{d}]}\left[\mathrm{min}^{-1}\right] \\
k_{2}\end{array}$} \\
\hline Fc-PU & 100 & 2.03 & 6 & 1.6548 & 0.00085 \\
ref-PU & 119 & 1.60 & 0 & - & 0.0002 \\
Fc-PMA & 133 & 1.10 & 1 & 0.0583 & 0.0064 \\
ref-PMA & 129 & 1.08 & 0 & - & 0.0086 \\
Fc-PMA2 & 43.6 & 1.12 & 1 & 0.0144 & 0.00098
\end{tabular}

[a] Determined by size-exclusion chromatography (SEC). [b] The dispersity $(\Theta)$ is determined from the ratio of $M_{w} / M_{n}$. [c] Average number of ferrocene moieties per chain calculated from the measured $M_{n}$ and the composition of the reaction mixture. [d] Obtained by modeling the $M_{n}$ decrease as shown by SEC data after the sonication experiments (0.75 $\mathrm{mg} \mathrm{mL}^{-1}$ in THF, $10.4 \mathrm{Wcm}^{-2}, 0^{\circ} \mathrm{C}$ ).

${ }^{13}$ C NMR spectroscopy (Figures S3-S22), size-exclusion chromatography (SEC) (Figures S23-S25), and elemental analysis (see SI). Upon ultrasonication at $0{ }^{\circ} \mathrm{C}$ under Ar (see SI for details), the $M_{\mathrm{n}}$ of Fc-PMA, determined by SEC, decreases much faster than that of ref-PMA, notably during the first minutes of the experiment (Figure 1). A largely bimodal profile is observed in the SEC traces (Figure $1 \mathrm{~b}$ ), showing a decrease of the most frequent species in Fc-PMA at an elution time of ca. 12 min (associated with an $M_{\mathrm{n}}$ of $133 \mathrm{kDa}$ ) in favor of a peak at an elution time of ca. $12.7 \mathrm{~min}\left(M_{\mathrm{n}}=\right.$ $52 \mathrm{kDa}$ ) (Figure 1b). This indicates that the chains are cleaved preferentially at their centers, so that $M_{\mathrm{n}}$ is roughly halved, similar to the previously reported PMA samples containing oxime sulfonate or benzocyclobutene as mechanophores. ${ }^{[8,37]}$ For Fc-PMA, this could be interpreted as preferential cleavage at the ferrocene entity versus cleavage of the $\mathrm{C}-\mathrm{C}$ bonds of the remainder of the polymer backbone, as the Fc unit is placed in the middle of the polymer. For refPMA (Figure S23) the results were similar, although the chain scission rate was significantly lower (Figure 1a).
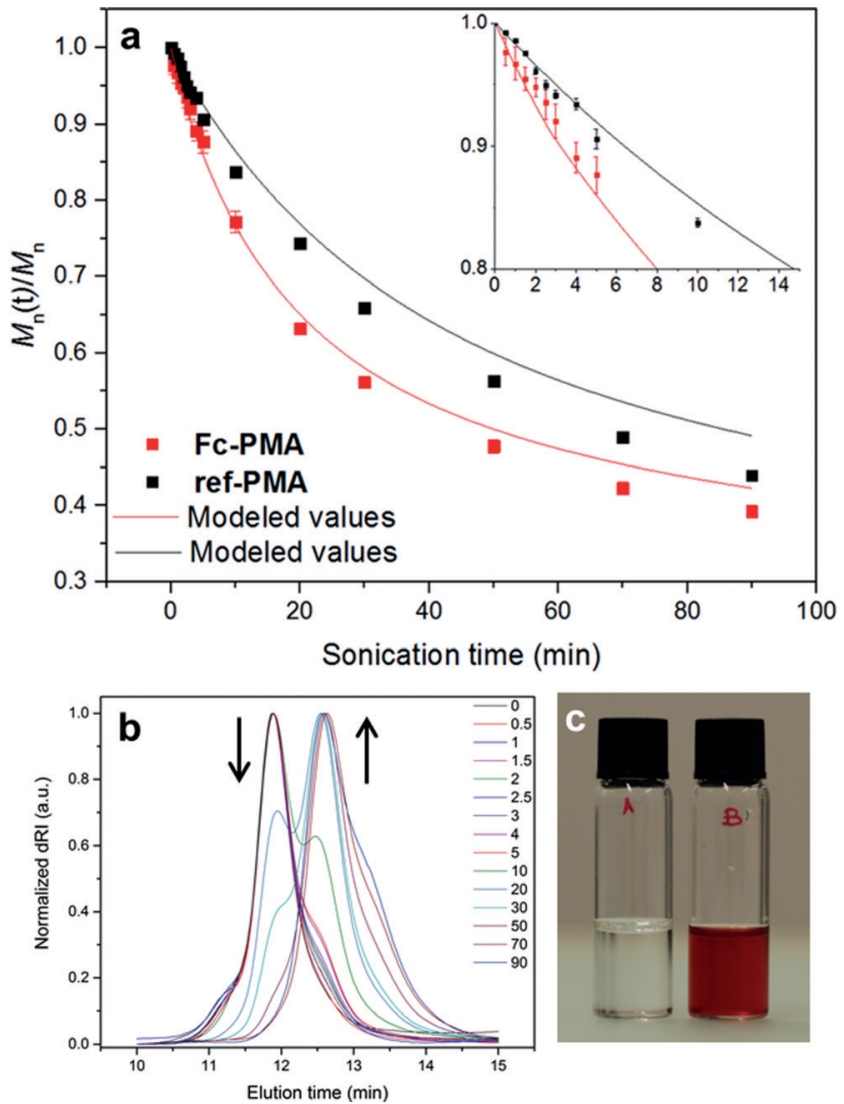

Figure 1. a) Decrease of the normalized molecular weight of ref-PMA (black) and Fc-PMA (red) as a function of time $\left(M_{n}(t) / M_{n}\right)$. Results are shown as averages of three experiments (red and black squares) with error bars representing the standard deviation at each data point. The inset shows a magnification of the data recorded in the first $15 \mathrm{~min}$. b) Size-exclusion chromatography (SEC) traces revealing an increase of the elution time (concomitant with a decrease of the molecular weight) upon ultrasonication of a Fc-PMA solution for the time indicated (in $\mathrm{min}$ ). A shoulder appearing after 50 min of sonication at an elution time of ca. $13.5 \mathrm{~min}\left(M_{n}=33 \mathrm{kDa}\right)$ seems to be associated with the repeated (nonspecific) cleavage of fragments formed by the first cleavage of the population of chains with the highest molecular weight (shoulder at an elution time around $11.2 \mathrm{~min}$ corresponding to an $M_{n}$ of $283 \mathrm{kDa}$ ). (Details about the correlation between elution time and polymer mass are provided in the Supporting Information). c) $\mathrm{KSCN}$ (dissolved in a 1:1 v/v mixture of $\mathrm{MeOH}$ and THF, $0.53 \mathrm{M}$ ) was added to the Fc-PMA solution before and after sonication, to show the formation of the red complex $\left.\left[\mathrm{Fe}(\mathrm{SCN})_{n}\left(\mathrm{H}_{2} \mathrm{O}\right)_{6-n}\right)\right]^{(3-n)+}$ after sonication and confirm the release of Fe ions. Fc-PMA solutions ( $2 \mathrm{mg} \mathrm{mL}^{-1}$ in THF) before sonication (sample A, pale yellow, left) and after 90 min of sonication (sample B, red solution). The red Fethiocyanate complex formed after sonication confirm the release of $\mathrm{Fe}$ ions solely upon sonication.

Further reference experiments with ferrocene and a lowmolecular-weight Fc-PMA2 with an $M_{\mathrm{n}}$ of ca. $40 \mathrm{kDa}$ show that these species neither dissociate nor release metal ions upon sonication, consistent with the fact that their $M_{\mathrm{n}}$ is below the limiting molecular weight $M_{\text {lim }}$ for chain scission of PMA during ultrasonication (see SI, Figures S25 and S26).$^{[40 b, 41]}$ To prove that the ultrasound-induced cleavage of Fc-PMA occurs at the Fc unit itself (and not at, e.g., the ester function), KSCN was added (without protecting the sample 
from air) to the sonicated solutions, resulting in the formation of the typical red $\mathrm{Fe}^{3+}$ complex $\left.\left[\mathrm{Fe}(\mathrm{SCN})_{n}\left(\mathrm{H}_{2} \mathrm{O}\right)_{6-n}\right)\right]^{(3-n)+}$ $(n=1-6)$ (Figure 2c). ${ }^{[42]}$ Similar experiments were performed with Fc-2, Fc-PMA2, and Fc-PMA3 (with one Fc at the chain end, see SI) as further controls. In none of these cases was a color change detected during and after sonication (Figures S47-S49).

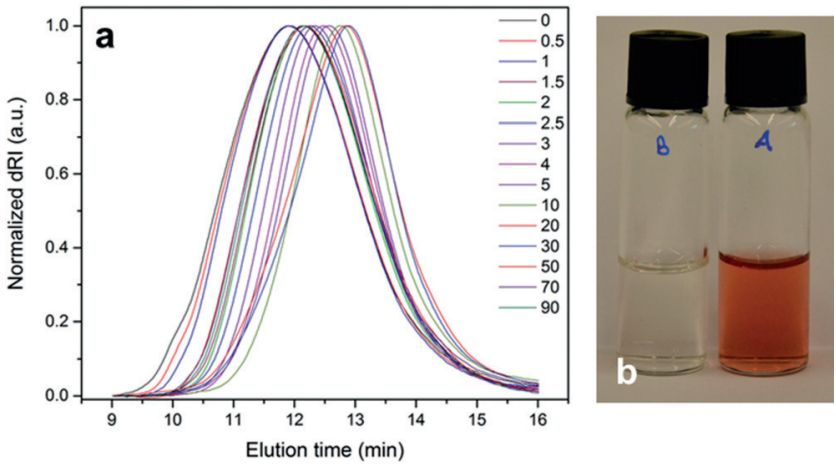

Figure 2. a) SEC traces of Fc-PU as a function of ultrasound irradiation time, revealing an increase of the elution time (decrease of the molecular weight); b) KSCN (dissolved in a 1:1 v/v mixture of $\mathrm{MeOH}$ and THF) was added to the solution of Fc-PU ( $0.75 \mathrm{mg} \mathrm{mL}^{-1}$ in THF), before (left, colorless solution) and after 90 min of sonication (right, red solution), to show the formation after sonication of the red complex $\left.\left[\mathrm{Fe}(\mathrm{SCN})_{n}\left(\mathrm{H}_{2} \mathrm{O}\right)_{6-n}\right)\right]^{(3-n)+}$ (due to the ferrocene breaking and the release of $\mathrm{Fe}$ ions).

The detection of $\mathrm{Fe}^{3+}$ with $\mathrm{KSCN}$ after sonication of FcPMA indicates that the release and oxidation of the metal ions took place. The cleavage of the Fc unit may occur either homolytically ${ }^{[43]}$ or heterolytically. ${ }^{[4]}$ Oxidation of the iron ion can take place in a half-sandwich type complex or after its release into the solution. While thiocyanate is able to act as a terminal ligand on monocyclopentadienyl complexes of $\mathrm{Fe},{ }^{[45]}$ the UV/Vis spectrum confirms the presence of $[\mathrm{Fe}$ $\left.\left.(\mathrm{SCN})_{n}\left(\mathrm{H}_{2} \mathrm{O}\right)_{6-n}\right)\right]^{(3-n)+}(n=1-6)$ (Figure S30)..$^{[42]}$

To gain insight into the kinetics of the ultrasound-induced chain scission of the polymers investigated, we analyzed the data with a recently developed kinetic model (see SI for details, Figures S33-S45) that allows a distinction between specific chain scission (i.e. cleavage of the mechanophore) and random chain cleavage at other positions. ${ }^{[46]}$ Considering that the polymer size influences the scission rate (which increases with the molecular weight), the model assumes that the $M_{\mathrm{n}}$ of the polymer decreases by following a pseudo-firstorder kinetic equation, with effective kinetic constants that change with time (see SI), on account of the fact that the polymer chains become shorter during the experiment. The mean values of these constants are compiled in Table 1. Figure 1 a shows the results of the model calculations (black and red curves) compared to the experimental evolution of the ratio of the number-average molecular weight $\left(M_{\mathrm{n}}(t)\right)$ and the initial number-average molecular weight $\left(M_{\mathrm{n}}\right)$ upon ultrasonication of solutions of ref-PMA (black squares) and Fc-PMA (red squares). The data describe the evolution of the entire population of polymer chains in the system, based on a previously tested approach. ${ }^{[46,47]}$ For ref-PMA, the average rate constant of $k_{2}=0.0086 \mathrm{~min}^{-1}$, derived from the initial slope of the curve, corresponds thus to the unspecific chain scission events. For Fc-PMA, two average rate constants of $k_{1}=0.058$ (associated with the ferrocene dissociation) and $k_{2}=0.0064 \mathrm{~min}^{-1}$ (corresponding to unspecific chain scission) were found (Table 1), hence the ferrocene cleavage is about 10 times more probable than the unspecific chain scission. The model can also be used to evaluate the fraction of ferrocene groups cleaved during the sonication process, which is about $52 \%$ in the case of Fc-PMA and less than $4 \%$ in the case of the low-molecular-weight Fc-PMA2 reference polymer.

In order to increase the number of metal-ion-release events per polymer chain, we also investigated polyurethanes, obtained by a polycondensation reaction (Scheme 2), with several ferrocene moieties randomly distributed in the polymer backbone. ${ }^{[38,39]}$ Thus, Fc-PU $\left(M_{n}=100 \mathrm{kDa}, Ð=\right.$ 2.03) with an average ferrocene content of $6 \mathrm{Fc}$ units per chain $(3 \mathrm{~mol} \% \mathrm{Fc})$, was synthesized and subjected to an ultrasonication experiment. The results were compared with those obtained for a ferrocene-free ref-PU of similar molecular weight and dispersity (see SI, Figure S21).

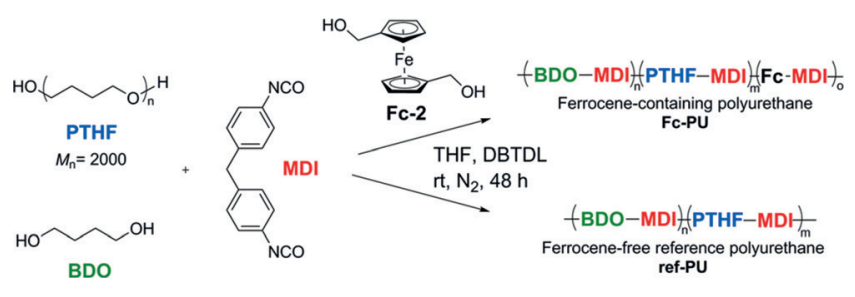

Scheme 2. Synthesis of ferrocene-containing polyurethane (Fc-PU) and ferrocene-free polyurethane (ref-PU) using 1,1'-di (hydroxymethyl)ferrocene (Fc-2) as a bifunctional monomer that was copolymerized with poly(tetrahydrofuran) (PTHF), methylene diphenyl diisocyanate (MDI), and 1,4-butanediol (BDO) (see SI). DBTDL=dibutyltin dilaurate.

The scission of Fc-PU upon sonication is indicated by a shift of a broad band observed in the SEC trace (Figure $2 \mathrm{a}$ ). Since each Fc-PU chain contains several ferrocene mechanophores that are statistically distributed along the backbone, the cleavage of an Fc entity can also lead to longer fragments that can then be cleaved again, even multiple times. As a result, the molecular weight distribution remains quite broad, with a wide range of species present. For the ferrocenefree ref-PU, the elution peak shifts as well, however more slowly, and the peak width decreases, likely indicating that the polymer breaks into more regular fragments (Figure S27). The same behavior was observed for similar polyurethanes featuring azo motifs as mechanophores. ${ }^{[46]}$

As a result of the multiple breaking of the chains and the release of more than one Fe ion per polymer chain, a lower concentration of Fc-PU $\left(0.75 \mathrm{mg} \mathrm{mL}^{-1}\right)$ as compared to FcPMA solution $\left(2 \mathrm{mg} \mathrm{mL}^{-1}\right)$ was sufficient in the detection of the release of iron as a red thiocyanate complex after sonication (Figure 2b). Again, the formation of the red complex $\left.\left[\mathrm{Fe}(\mathrm{SCN})_{n}\left(\mathrm{H}_{2} \mathrm{O}\right)_{6-n}\right)\right]^{(3-n)+}(n=1-6)$ was proven by UV/Vis spectroscopy (Figure S31). ${ }^{[42]}$ Videos of the Fc-PU and the corresponding reference (ref-PU, Fc, and KSCN 
alone) color-change experiments are available in the Supporting Information.

We applied a similar kinetic model to the molecular weight data extracted from the ultrasound-induced chain scission experiments of PU as with Fc-PMA (Figure S46). The larger number of Fc moieties in Fc-PU and their random distribution along the chains increase their probability of being cut in subsequent scission events. The molecular weight decrease observed upon ultrasonication of ref-PU, void of Fc moieties, can be described by a single rate constant of $k_{2}=$ $0.0002 \mathrm{~min}^{-1}$, ascribed to the nonspecific bond cleavage. This is much lower than for the nonspecific bond cleavage in refPMA. For Fc-PU, the model reveals the overlay of two types of chain scission events that are characterized by average rate constants of $k_{1}=1.65$ and $k_{2}=0.00085 \mathrm{~min}^{-1}$, which can be associated with the dissociation of the (weaker) ferrocene mechanophore and unspecific chain scission, respectively. The difference between the values of $k_{2}$ for ref-PU and FcPU can be explained by the fact that the constants depend on the initial molecular weight of the polymer and its constitution. It is important to highlight that the value of $k_{l}$ determines the initial slope of the molecular weight evolution as a function of time, as well as the final consumption of ferrocene moieties. The $k_{1}$ value for Fc-PU is thus ca. three orders of magnitude higher than the unspecific rate of scission $k_{2}$ (Table 1), and confirms the role of Fc groups as effective mechanophores. A comparison of the chain scission data for Fc-PMA and Fc-PU shows that the scission rate constants associated with the cleavage of the Fc moieties are much larger in PU than in PMA, and always much larger than that of nonspecific scission rate constants in both polymers (Table 1). This can be accounted for by the larger number of Fc units in Fc-PU that are each preferentially cleaved with respect to the other bonds in the polymer backbone as well as the chemical differences between PMA and PU. The above model also permits to estimate that about $25 \%$ of the $\mathrm{Fc}$ moieties are cleaved at the end of sonication in the Fc-PU polymer, which is qualitatively confirmed by a titration experiment (see SI, Titration experiment).

Thus, ultrasonication can selectively cleave Fc-containing polymers at the ferrocene moieties, triggering metal ion release and oxidation that can be evidenced by the formation of the red thiocyanate complex (Figures $1 \mathrm{c}, 2 \mathrm{~b}$ and movies in SI). In order to exclude that the metal iron release from FcPU and Fc-PMA was due to a thermal effect upon sonication, control experiments with KSCN-containing solutions of FcPU, Fc-PMA and Fc-2 were heated to reflux for 24 hours without sonication. In none of the cases did we observe a color change, proving that the ferrocene scission is not thermally induced.

Metal ion release was further proven by a possible application, namely the generation of the dark blue pigment Prussian blue on demand, which is used, for example, in medical applications for the absorption of toxic thallium ions or radioactive cesium. ${ }^{[48]}$ To achieve this, we added $\mathrm{K}_{4}[\mathrm{Fe}$ $\left.(\mathrm{CN})_{6}\right](0.0414 \mathrm{M})$ to a solution of Fc-PU2 containing $12 \% \mathrm{Fc}$ $\left(0.75 \mathrm{~g} \mathrm{~mol}^{-1}, M_{\mathrm{n}}=46 \mathrm{kDa}, Ð=2.6\right)$, which was prepared by a procedure similar to that for Fc-PU with $3 \% \mathrm{Fc}$, described above (Figures S15 and S25). During the sonication of Fc-
PU2, we observed the formation of a blue colloidal solution (Prussian blue), which confirms the release and oxidation (but not the sequence of these events) of iron ions (Figure 3). A control experiment with ref-PU or $\mathbf{F c}$ with $\mathrm{K}_{4}\left[\mathrm{Fe}(\mathrm{CN})_{6}\right]$ under sonication did not yield the blue pigment (Figures S50 and S51), nor did Fc-PU2 in presence of hexacyanoferrate(II) without sonication (Figure $3 \mathrm{a}$ ). Although the $M_{\mathrm{n}}$ of Fc-PU2 of $46 \mathrm{kDa}$ is likely close to the limit of $M_{n}$ for studying the molecular weight decrease upon sonication, it was nevertheless shown to work as a further example of color change after the oxidative iron ion release.

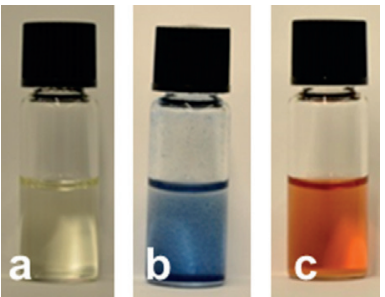

Figure 3. Color change of the solution of Fc-PU2 (containing 12\% Fc) a) before sonication in the presence of $\mathrm{K}_{4}\left[\mathrm{Fe}(\mathrm{CN})_{6}\right]$ ), b) after sonication in presence of $\mathrm{K}_{4}\left[\mathrm{Fe}(\mathrm{CN})_{6}\right]$, and $\mathrm{c}$ ) after sonication with $\mathrm{KSCN}$. In the second case the blue color indicates the formation of the Prussian blue. These experiments were carried out after ultrasonication (90 $\mathrm{min})$ of the polymer.

In conclusion, we have used for the first time ferrocene derivatives as mechanophores in polymers with the ability to break and to release the central metal ion under mechanical stress in solution. Two competitive scission events were observed in Fc-containing polymers: the cleavage of the Fc mechanophore $\left(k_{1}\right)$ and the cleavage of random bonds $\left(k_{2}\right)$. The scission for Fc is at least 10 times more favored than unspecific cleavage. It is thus conceivable to use also other metallocenes as mechanophores for selective metal ion release. ${ }^{[49]}$ Furthermore, the triggered release of the metal ion from ferrocene can be used to induce a color change and/ or the formation of a pigment for, for example, analytical and medical applications. It can be envisaged to use this unique type of polymer scission also in catalysis, as iron ions are highly active catalysts for different organic reactions, such as intramolecular hydroalkoxylation and hydroamination reactions of allenes. ${ }^{[50]}$ These materials have the potential to mechano-generate free base in solution, exploiting the cyclopentadienyl anion, formed after the ferrocene breaking, even though we cannot exclude rapid protonation or the formation

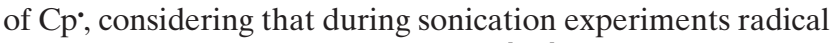
species can also be easily generated. ${ }^{[8,44]}$ Further studies are under way to determine the scission mechanism of the metallocene and the use of such a metal-release-on-demand system for applications in catalysis.

\section{Acknowledgements}

This work was supported by the National Center of Competence in Research "Bio-Inspired Materials" (Project 
141849) of the Swiss National Science Foundation, the Fribourg Center for Nanomaterials (FriMat), the Adolphe Merkle Foundation, and the University of Fribourg. The research leading to these results has received funding from the European Research Council under the European Union's Seventh Framework Programme (FP7/2007-2013)/ERC grant agreement $n^{\circ}$ 291490-MERESPO. We thank Prof. Bernd Giese for fruitful discussions.

\section{Conflict of interest}

The authors declare no conflict of interest.

Keywords: mechanophores · organometallic chemistry · polymers $\cdot$ stimuli-responsive polymers

How to cite: Angew. Chem. Int. Ed. 2018, 57, 11445-11450 Angew. Chem. 2018, 130, 11616-11621

[1] H. Koshima, N. Ojima, H. Uchimoto, J. Am. Chem. Soc. 2009 , $131,6890-6891$.

[2] R. P. Wool, Soft Matter 2008, 4, 400-418.

[3] O. Azzaroni, B. Trappmann, P. van Rijn, F. Zhou, B. Kong, W. T. Huck, Angew. Chem. Int. Ed. 2006, 45, 7440-7443; Angew. Chem. 2006, 118, 7600-7603.

[4] J. Li, C. Nagamani, J. S. Moore, Acc. Chem. Res. 2015, 48, 2181 2190.

[5] M. A. C. Stuart, W. T. Huck, J. Genzer, M. Müller, C. Ober, M. Stamm, G. B. Sukhorukov, I. Szleifer, V. V. Tsukruk, M. Urban, Nat. Mater. 2010, 9, 101.

[6] a) M. Rubner, Macromolecules 1986, 19, 2129-2138; b) D. A Davis, A. Hamilton, J. Yang, L. D. Cremar, D. Van Gough, S. L. Potisek, M. T. Ong, P. V. Braun, T. J. Martínez, S. R. White, Nature 2009, 459, 68.

[7] C. E. Diesendruck, B. D. Steinberg, N. Sugai, M. N. Silberstein, N. R. Sottos, S. R. White, P. V. Braun, J. S. Moore, J. Am. Chem. Soc. 2012, 134, 12446-12449.

[8] C. Nagamani, H. Liu, J. S. Moore, J. Am. Chem. Soc. 2016, 138, $2540-2543$.

[9] J. M. Clough, A. Balan, T. L. van Daal, R. P. Sijbesma, Angew. Chem. Int. Ed. 2016, 55, 1445-1449; Angew. Chem. 2016, 128, $1467-1471$.

[10] a) M. B. Larsen, A. J. Boydston, J. Am. Chem. Soc. 2014, 136 1276-1279; b) A. N. Koo, H. J. Lee, S. E. Kim, J. H. Chang, C. Park, C. Kim, J. H. Park, S. C. Lee, Chem. Commun. 2008, 6570 6572.

[11] J. Hu, S. Liu, Macromolecules 2010, 43, 8315-8330.

[12] Y. Qiu, K. Park, Adv. Drug Delivery Rev. 2001, 53, 321-339.

[13] J. F. Mano, Adv. Eng. Mater. 2008, 10, 515-527.

[14] a) A. Piermattei, S. Karthikeyan, R. P. Sijbesma, Nat. Chem. 2009, 1, 133-137; b) Y. Lu, Y. Mei, M. Drechsler, M. Ballauff, Angew. Chem. Int. Ed. 2006, 45, 813-816; Angew. Chem. 2006, $118,827-830$.

[15] K. L. Berkowski, S. L. Potisek, C. R. Hickenboth, J. S. Moore, Macromolecules 2005, 38, 8975-8978.

[16] H. M. Klukovich, Z. S. Kean, A. L. B. Ramirez, J. M. Lenhardt, J. Lin, X. Hu, S. L. Craig, J. Am. Chem. Soc. 2012, 134, $9577-$ 9580.

[17] M. J. Robb, J. S. Moore, J. Am. Chem. Soc. 2015, 137, $10946-$ 10949.

[18] Y. Chen, A. Spiering, S. Karthikeyan, G. W. Peters, E. Meijer, R. P. Sijbesma, Nat. Chem. 2012, 4, 559.

[19] Z. Wang, Z. Ma, Y. Wang, Z. Xu, Y. Luo, Y. Wei, X. Jia, Adv. Mater. 2015, 27, 6469-6474.
[20] a) C. R. Hickenboth, J. S. Moore, S. R. White, N. R. Sottos, J. Baudry, S. R. Wilson, Nature 2007, 446, 423; b) Z. a. Li, R. Toivola, F. Ding, J. Yang, P. N. Lai, T. Howie, G. Georgeson, S. H. Jang, X. Li, B. D. Flinn, Adv. Mater. 2016, 28, 6592-6597; c) K. Imato, T. Kanehara, T. Ohishi, M. Nishihara, H. Yajima, M. Ito, A. Takahara, H. Otsuka, ACS Macro Lett. 2015, 4, 1307-1311; d) M. B. Larsen, A. J. Boydston, J. Am. Chem. Soc. 2013, 135, 8189-8192; e) A. L. B. Ramirez, Z. S. Kean, J. A. Orlicki, M. Champhekar, S. M. Elsakr, W. E. Krause, S. L. Craig, Nat. Chem. 2013, 5, 757.

[21] A. P. Haehnel, Y. Sagara, Y. C. Simon, C. Weder, in Polym. Mechanochem., Springer, Berlin, 2015, pp. 345 - 375.

[22] S. Karthikeyan, S. L. Potisek, A. Piermattei, R. P. Sijbesma, J. Am. Chem. Soc. 2008, 130, 14968-14969.

[23] a) V. A. Friese, D. G. Kurth, Curr. Opin. Colloid Interface Sci. 2009, 14, 81 -93; b) J. M. Paulusse, R. P. Sijbesma, Angew. Chem. Int. Ed. 2004, 43, 4460-4462; Angew. Chem. 2004, 116, $4560-$ 4562.

[24] R. T. Jakobs, S. Ma, R. P. Sijbesma, ACS Macro Lett. 2013, 2, $613-616$.

[25] a) A. G. Tennyson, K. M. Wiggins, C. W. Bielawski, J. Am. Chem. Soc. 2010, 132, 16631-16636; b) K. M. Wiggins, T. W. Hudnall, A. G. Tennyson, C. W. Bielawski, J. Mater. Chem. 2011, 21, 8355-8359.

[26] D. W. Balkenende, S. Coulibaly, S. Balog, Y. C. Simon, G. L. Fiore, C. Weder, J. Am. Chem. Soc. 2014, 136, 10493-10498.

[27] a) W. Weng, J. B. Beck, A. M. Jamieson, S. J. Rowan, J. Am. Chem. Soc. 2006, 128, 11663 -11672; b) J. B. Beck, S. J. Rowan, J. Am. Chem. Soc. 2003, 125, $13922-13923$.

[28] M. Encina, E. Lissi, M. Sarasua, L. Gargallo, D. Radic, J. Polym. Sci., Part C 1980, 18, 757-760.

[29] S.-H. Jeong, J.-H. Ko, J.-B. Park, W. Park, J. Am. Chem. Soc. 2004, 126, 15982-15983.

[30] E. S. Domalski, E. D. Hearing, J. A. Martinho Simões, Data compilation copyright by the U.S. Secretary of Commerce on behalf of the USA, National Institute of Standards and Technology (NIST).

[31] a) N. Cohen, J. Phys. Chem. Ref. Data 1996, 25, 1411-1481; b) J. R. Chipperfield, J. C. Sneyd, D. E. Webster, J. Organomet. Chem. 1979, 178, 177-189; c) F. A. Cotton, G. Wilkinson, J. Am. Chem. Soc. 1952, 74, 5764-5766.

[32] a) Y. Han, K. Cheng, K. A. Simon, Y. Lan, P. Sejwal, Y.-Y. Luk, J. Am. Chem. Soc. 2006, 128, 13913-13920; b) D. R. Van Staveren, N. Metzler-Nolte, Chem. Rev. 2004, 104, 5931-5986; c) J. Eppinger, K. R. Nikolaides, M. Zhang-Presse, F. A. Riederer, G. W. Rabe, A. L. Rheingold, Organometallics 2008, 27, 736740.

[33] a) F. Otón, A. Espinosa, A. Tárraga, P. Molina, Organometallics 2007, 26, 6234-6242; b) M. Nakayama, T. Ihara, K. Nakano, M. Maeda, Talanta 2002, 56, 857-866.

[34] a) R. Gómez Arrayás, J. Adrio, J. C. Carretero, Angew. Chem. Int. Ed. 2006, 45, 7674-7715; Angew. Chem. 2006, 118, 78367878; b) O. Riant, O. Samuel, H. B. Kagan, J. Am. Chem. Soc. 1993, 115, 5835-5836.

[35] P. Molina, A. Tárraga, A. Caballero, Eur. J. Inorg. Chem. 2008, $3401-3417$.

[36] a) E. Hillard, A. Vessières, L. Thouin, G. Jaouen, C. Amatore, Angew. Chem. Int. Ed. 2006, 45, 285-290; Angew. Chem. 2006, 118, 291-296; b) X. Peng, H. He, J. Xia, Z. Lou, G. Chang, X. Zhang, S. Wang, Tetrahedron Lett. 2014, 55, 3541-3544; c) E. Hillard, A. Vessieres, F. Le Bideau, D. Plażuk, D. Spera, M. Huche, G. Jaouen, ChemMedChem 2006, 1, 551-559.

[37] S. L. Potisek, D. A. Davis, N. R. Sottos, S. R. White, J. S. Moore, J. Am. Chem. Soc. 2007, 129, 13808-13809.

[38] M. A. Ayer, Y. C. Simon, C. Weder, Macromolecules 2016, 49, $2917-2927$. 
[39] B. R. Crenshaw, C. Weder, Macromolecules 2006, 39, $9581-$ 9589.

[40] a) A. L. B. Ramirez, Z. S. Kean, J. A. Orlicki, M. Champhekar, S. M. Elsakr, W. E. Krause, S. L. Craig, Nat. Chem. 2013, 5, $757-$ 761; b) M. M. Caruso, D. A. Davis, Q. Shen, S. A. Odom, N. R. Sottos, S. R. White, J. S. Moore, Chem. Rev. 2009, 109, $5755-$ 5798.

[41] G. J. Price, P. F. Smith, Polym. 1993, 34, 4111-4117.

[42] J. F. Below Jr, R. E. Connick, C. P. Coppel, J. Am. Chem. Soc. 1958, 80, 2961-2967.

[43] C. R. Kutal, Y. Yamaguchi, US Patent 6,127,445 (2000).

[44] Q. M. Phung, S. Vancoillie, K. Pierloot, J. Chem. Theory Comput. 2014, 10, $3681-3688$.

[45] a) T. E. Sloan, A. Wojcicki, Inorg. Chem. 1968, 7, 1268-1273;

b) D. A. Brown, N. J. Fitzpatrick, W. K. Glass, P. K. Sayal, Organometallics 1984, 3, 1137-1144.
[46] "Stimuli-Responsive Azo-Containing Polymeric Materials", M. A. Ayer, PhD Thesis, University of Fribourg 2018, № 2038.

[47] M. Schaefer, B. Icli, C. Weder, M. Lattuada, A. F. Kilbinger, Y. C. Simon, Macromolecules 2016, 49, 1630-1636.

[48] K. Dunbar, R. A. Heintz, Prog. Inorg. Chem. 1997, 45, 283 - 392.

[49] M. Swart, Inorg. Chim. Acta 2007, 360, 179-189.

[50] M. S. Jung, W. S. Kim, Y. H. Shin, H. J. Jin, Y. S. Kim, E. J. Kang, Org. Lett. 2012, 14, $6262-6265$.

Manuscript received: March 23, 2018

Revised manuscript received: June 12, 2018

Accepted manuscript online: June 13, 2018

Version of record online: July 26, 2018 